\title{
Autoeficácia e sucesso na transição para o trabalho: Um estudo longitudinal
}

\author{
Diana Aguiar Vieira \\ CEOS.PP, ISCAP, Politécnico do Porto, Porto, Portugal \\ Maria Theotonio \\ Universidade São Francisco, Campinas-SP, Brasil
}

\section{Resumo}

O sucesso na transição do ensino superior para o trabalho é influenciado por uma multiplicidade de fatores associados ao indivíduo, ao seu contexto, bem como à interação entre ambos. O Modelo Social Cognitivo da Transição para o Trabalho organiza conceptualmente a complexidade desta transição e orienta a sua investigação. O presente estudo visa avaliar se a autoeficácia na transição no trabalho prediz o sucesso obtido nesta transição, um ano após a conclusão do curso. Os resultados evidenciam o potencial preditivo da autoeficácia relativamente à satisfação com o percurso académico-profissional e com o trabalho, o que vem salientar a pertinência de intervenções psicoeducativas com o objetivo de desenvolver a autoeficácia na transição para o trabalho em estudantes do ensino superior.

Palavras-chave: Autoeficácia, ensino superior, planejamento de carreira, trabalho, teoria social cognitiva

\section{Abstract: Self-efficacy and transition-to-work success: A longitudinal study}

Success in the transition from higher education to work is influenced by a multiplicity of factors associated with the individual, his/her context, as well as their interaction. The Transition-to-Work Social Cognitive Model conceptually organizes the complexity of this transition and guides its research. The present study aims to evaluate if transitionto-work self-efficacy predicts the success obtained in this transition, one year after obtaining a bachelor degree. The results show the predictive potential of self-efficacy in relation to satisfaction with the academic-professional course and the work, which highlights the pertinence of psychoeducational interventions aimed at developing self-efficacy in the transition to work of students from higher education institutions.

Keywords: Self-efficacy, higher education, career planning, work, social cognitive theory

\section{Resumen: Autoeficacia y éxito en la transición al trabajo: Un estudio longitudinal}

El éxito en la transición de la enseñanza superior al trabajo está determinado por una multiplicidad de factores asociados con el individuo, su contexto y la interacción entre ambos. El Modelo Social Cognitivo de la Transición al Trabajo organiza conceptualmente la complejidad de esta transición y orienta su investigación. El presente estudio pretende evaluar si la autoeficacia en la transición al trabajo predice el éxito obtenido en esta transición, un año después de la conclusión de la carrera universitaria. Los resultados evidencian el potencial predictivo de la autoeficacia respecto a la satisfacción con la trayectoria académico-profesional y con el trabajo, lo que viene a subrayar la pertinencia de intervenciones psicoeducativas con el propósito de desarrollar la autoeficacia en la transición al trabajo en estudiantes de enseñanza superior.

Palabras clave: Autoeficacia, enseñanza superior, planificación de carrera, trabajo, teoría social cognitiva

\footnotetext{
${ }^{1}$ Endereço para correspondência: Rua Jaime Lopes Amorim, s/n, 4465-004, S. Mamede de Infesta, Porto, Portugal. Fone: +351 229050000. E-mail: dianavieira@iscap.ipp.pt
} 
Uma economia globalizada e baseada no conhecimento, aliada à velocidade e magnitude dos avanços tecnológicos, são fatores que têm contribuído para a crescente complexidade dos contextos de trabalho. Com origem no contexto militar dos Estados Unidos da América, o acrónimo VUCA - Volatility, Uncertainty, Complexity, Ambiguity - refere-se à volatilidade, incerteza, complexidade e ambiguidade que caracterizam o mundo do Século XXI (Bernstein, 2014). Pelo seu potencial heurístico, a expressão VUCA rapidamente se generalizou na literatura relacionada com as organizações e com o trabalho. No âmbito da orientação vocacional e gestão da carreira, o enquadramento do mundo VUCA é útil para se compreender os desafios colocados às pessoas que procuram "navegar" no mundo do trabalho e da formação, ao longo da vida (Shaffer \& Zalewski, 2011; Vieira, 2017). Efetivamente, a carreira individual caracteriza-se por "um percurso pontuado por descontinuidades - promoções, desemprego, transição da formação para o trabalho, investimentos na formação, reconversão profissional - que obrigam o indivíduo a fazer escolhas e a reposicionar a sua relação com o mundo laboral" (Campos \& Coimbra, 1992, p.5). Por sua vez, tal relação - eminentemente dinâmica - caracteriza-se por um processo contínuo de "negociação entre o indivíduo e o meio, ou, dito de outro modo, de exercício do poder pessoal na interação com o poder social" (Coimbra, Parada \& Imaginário, 2001, p.38).

Os desafios com os quais os jovens se confrontam, quando pretendem iniciar a sua vida profissional, nunca foram tão exigentes. Nesta dialética entre o "poder pessoal na interação com o poder social", isto é, entre aquilo que um jovem pode fazer para obter o que deseja em termos profissionais e a estrutura de oportunidades de trabalho existentes no seu meio, a autoeficácia tem-se evidenciado como um constructo útil associado à agência pessoal, isto é, à capacidade do indivíduo exercer influência sobre o seu meio (Bandura, 1997). Bandura define a autoeficácia como as crenças relativas às capacidades pessoais para realizar com sucesso um determinado comportamento, propondo que estas influenciam o modo como as pessoas pensam, sentem, se automotivam e se comportam (Bandura, 1986, 1991). Por conseguinte, a autoeficácia abarca as crenças pessoais sobre as capacidades para mobilizar a motivação, os recursos cognitivos e os cursos de ação necessários para se exercer controle sobre acontecimentos ao longo da vida (Wood $\&$ Bandura, 1989). Assim, a eficácia pessoal é um aspeto dinâmico do "self" que interage de forma complexa com o contexto, bem como com outros mecanismos motivacionais e autorregulatórios.

O Modelo Social Cognitivo da Transição para o Trabalho (MSTT) (Vieira, 2012) situa a autoeficácia num quadro de referência abrangente que explicita a interação dinâmica entre fatores individuais, contextuais e psicológicos no processo de transição para o trabalho. Fundamentado na Teoria Social Cognitiva da Carreira proposta por Lent, Brown e Hackett (1994), o MSTT, representado na Figura 1, apresenta como contributo original a aplicação da Teoria Social Cognitiva à transição para o trabalho.

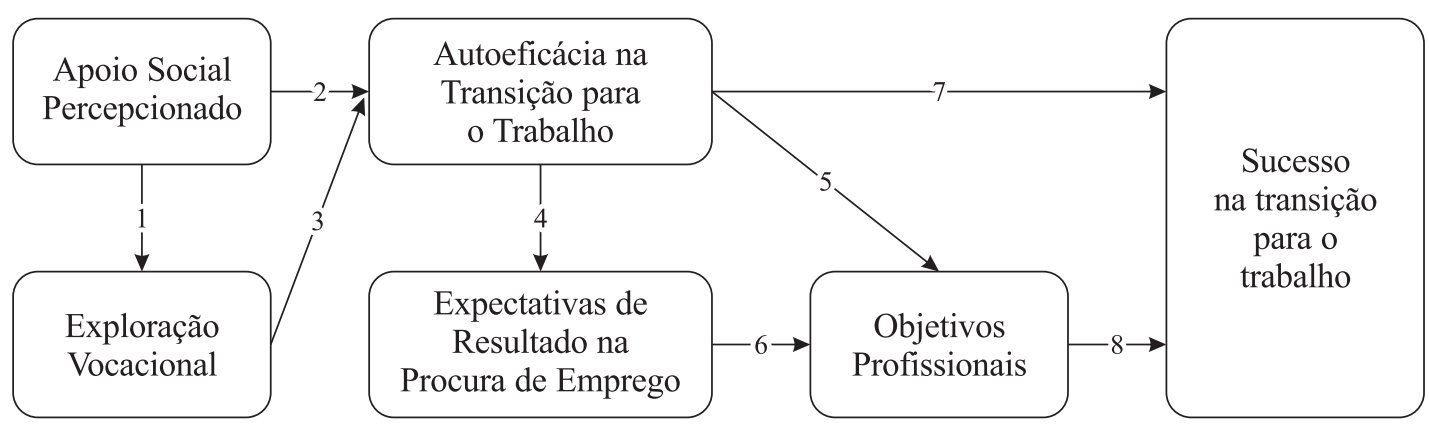

Figura 1. Modelo Social Cognitivo da Transição para o Trabalho (Adaptado de Vieira, 2012)

O MSTT preconiza que o processo de vivência psicológica da transição para o trabalho é influenciado por um conjunto de fatores individuais e contextuais que interagem e que exercem a sua influência sobre toda a dinâmica desta transição. A representação gráfica desta característica do
MSTT é explicitada na identificação dos fatores através da sinalização das "influências individuais e contextuais" no esquema apresentado na Figura 1. Tais influências podem ser definidas como o conjunto dos aspetos da pessoa que a caracterizam de um ponto de vista objetivo, isto é, que 
dizem respeito a atributos externamente observáveis. Por exemplo, as características individuais poderão ser o sexo e a área de formação. As habilitações académicas dos pais e a taxa de desemprego do local onde a pessoa habita são exemplos de características contextuais.

Por sua vez, os vetores representados na Figura 1, e identificados pelos números de 1 a 8 , correspondem às hipóteses acerca das relações entre os seus elementos constituintes. Entre estes, o apoio social percepcionado consiste na perceção que a pessoa tem acerca do apoio social que usufrui, o que está em consonância com a nossa perspetiva que privilegia os significados atribuídos pela pessoa à sua realidade subjetiva e construída, e não às características mais objetivas como, por exemplo, o número de pessoas que fazem parte da sua rede de apoio social. Aliás, neste modelo, a influência dos fatores contextuais acontece em função da perceção pessoal do contexto, isto é "o contexto oferece, fornece elou proporciona algo ao organismo, desde que este consiga percepcioná-lo como tal" (Vondracek, Lerner \& Schulenberg, 1986, p.38). Efetivamente, esta perspetiva não minimiza a importância das características objetivas do contexto mas enfatiza o papel ativo da pessoa enquanto intérprete do seu contexto, realçando a relevância do significado pessoalmente construído.

A exploração vocacional engloba um conjunto de atividades nas quais a pessoa se envolve e que promovem um maior conhecimento acerca de si própria e do meio laboral e/ou formativo (Blustein, 1992; 1997), representando, no MSTT, as aprendizagens vocacionais relevantes para a transição para o trabalho.

Por sua vez, o apoio social e a exploração são duas dimensões que se associam, sendo vários os autores a preconizar que o apoio emocional e instrumental emerge como um importante antecedente da exploração, seja em termos gerais (por exemplo, Bowlby, 1982), seja no domínio do desenvolvimento vocacional (Blustein, Prezioso \& Schultheiss, 1995; Young, 1994). Posto isto, o vetor 1 espelha a hipótese de que o apoio social influencia a exploração vocacional, isto é, o apoio social percebido possui um efeito direto e positivo sobre a exploração vocacional.

Os vetores 2 e 3 do MSTT representam as hipóteses de que tanto o apoio social como a exploração vocacional funcionam como fontes de autoeficácia. Efetivamente, a Teoria Social Cognitiva de Bandura $(1986 ; 1997)$ identifica a persuasão verbal como uma das fontes de autoeficácia e, no MSTT, esta fonte é enquadrada no apoio social (vetor 2). Adicionalmente, as atividades de exploração vocacional, ao propiciar experiências de aprendizagem - quer diretas, quer por observação - são também consideradas como fontes de autoeficácia na medida em que poderão permitir o desenvolvimento de mestria em determinadas atividades, assim como o acesso a modelos cujas experiências de sucesso poderão ter impacto na autoeficácia do indivíduo (vetor 3).

Por sua vez, a autoeficácia contribui para as expectativas de resultado na procura de emprego (vetor 4) bem como para a formulação de objetivos profissionais (vetor 5), sendo os objetivos que o sujeito define para si próprio, bem como o progresso na sua prossecução, influenciados também pelas expectativas de resultado (vetor 6). Efetivamente, quanto mais valorizados forem os resultados antecipados, maior a probabilidade do indivíduo adotar determinados objetivos profissionais.

A Teoria Social Cognitiva da Carreira e, mais precisamente, o Modelo do Desempenho proposto por Lent, Brown e Hackett (1994) defende a existência de uma relação positiva entre as crenças de autoeficácia e o desempenho académico/profissional. Isto é, as crenças positivas de autoeficácia promovem a qualidade do desempenho. Pelo contrário, "baixas crenças de autoeficácia poderão fazer-se acompanhar de um discurso interno negativo e de respostas de ansiedade, as quais interferem na concentração na tarefa a desempenhar, prejudicando o desempenho." (Betz, 2004, p.342). Assim, incluímos o vetor 7 assumindo que a autoeficácia na transição para o trabalho possui um papel preponderante no sucesso desta transição. De realçar que, no MSTT, o desempenho é abordado em sentido lato como o sucesso na transição para o trabalho. Desta forma, para a avaliação deste sucesso poder-se-ão utilizar vários indicadores tais como, por exemplo, a situação laboral (empregado vs desempregado), o salário, a satisfação com o trabalho, entre outros. Finalmente, tendo em conta as relações preconizadas entre objetivos e desempenho (Bandura, 1986, 1989; Locke \& Latham, 2002; Schunk, 1989; Wood \& Bandura, 1989), o MSTT propõe que os objetivos na transição para o trabalho possuem um efeito direto e positivo no sucesso desta transição (vetor 8).

Concluindo, o MSTT serve como uma base conceptual abrangente e orientadora da investigação acerca do processo de transição da formação para o trabalho, numa perspetiva Social Cognitiva. Uma vez que os conceitos e respetivos vetores representam oito hipóteses, poder-se-ão realizar estudos do MSTT que sejam totais (caso todos os conceitos e relações sejam consideradas) ou parciais (caso se considerem apenas algumas das suas partes).

\section{Autoeficácia e Sucesso na Transição para o Trabalho}

Hernández-Fernaud, Ramos-Sapena, Negrín, Rosa e Hernández (2011) realizaram um estudo com o objetivo 
de analisar a relação entre a autoeficácia na procura de emprego e a empregabilidade percebida. Este estudo foi feito com uma amostra de 462 estudantes universitários, sendo $52,7 \%$ do último ano, $30,3 \%$ do penúltimo ano e $17 \%$ já graduados. A maior parte da amostra foi composta por mulheres $(74 \%)$ e as idades variaram entre 19 e 30 anos, com média de 23,3 anos. Os resultados revelaram uma relação positiva entre a autoeficácia na procura de emprego e a perceção de empregabilidade, não se tendo constatado diferenças entre os sexos nem entre o ano do curso ou graduação concluída.

O estudo realizado por Pelissoni (2007) visou identificar a relação entre os comportamentos de exploração de carreira e a autoeficácia na transição para o trabalho em estudantes concluintes de ensino superior. Este estudo, embora transversal, evidenciou que os estudantes que já trabalhavam apresentavam uma autoeficácia na transição para o trabalho mais elevada do que os que não trabalhavam, nomeadamente, nas dimensões de autoeficácia na adaptação para o trabalho e de autoeficácia na procura por emprego.

Outro estudo transversal foi realizado por Ballout (2009) numa amostra de 180 funcionários de 35 bancos libaneses, com diferentes ocupações funcionais, idades compreendidas entre 33 e 43 anos, sendo que as mulheres representaram $40 \%$ da amostra. O compromisso com a carreira foi preditor do nível salarial e da satisfação no trabalho nos trabalhadores com autoeficácia média e elevada, mas não entre os trabalhadores com baixa autoeficácia.

No estudo longitudinal realizado por Pinquart, Juang e Silbereisen (2003), investigou-se a autoeficácia acadêmica no período dos 12 aos 15 anos e se estas estavam associadas ao desemprego e a satisfação no trabalho aos 21 anos de idade. Concluiu-se que indivíduos com níveis mais elevados de autoeficácia acadêmica entre os 12 e 15 anos experimentaram menos desemprego e relataram uma maior satisfação no trabalho.

Noutro estudo longitudinal, realizado na Alemanha, Abele e Spurk (2009) verificaram que a autoeficácia profissional, avaliada no início da carreira profissional, teve um efeito positivo no salário (três e sete anos depois) e na satisfação no trabalho (sete anos depois). Isto é, níveis mais elevados de autoeficácia profissional no início da carreira associaram-se a salários mais elevados e a uma maior satisfação profissional.

No estudo longitudinal do MSTT, realizado por Vieira (2012), a autoeficácia na transição para o trabalho, avaliada em estudantes no último ano da formação superior, foi capaz de predizer, um ano depois, o sucesso na transição no trabalho. Mais concretamente, a autoeficácia demonstrou um poder preditivo da situação laboral, da satisfação com o percurso académico-profissional, da satisfação no trabalho e do nível salarial.

O presente estudo tem por objetivo avaliar se a autoeficácia na transição no trabalho de estudantes no último ano do Ensino Superior prediz o sucesso obtido nesta transição, um ano após a conclusão do curso.

\section{Método}

\section{Participantes}

Este estudo envolveu 210 participantes, $61 \%$ do sexo feminino $(n=127)$, com uma média etária de 21 anos e meio (desvio padrão $= \pm 1$ ano). Todos os participantes possuem graduação na área de Ciências Sociais, obtida na mesma instituição de ensino superior localizada na Região Norte de Portugal e nenhum dos participantes trabalhou durante a realização do curso de graduação.

Quanto à situação académica e/ou profissional após a conclusão da graduação, $50 \%$ estavam trabalhando, $27 \%$ dedicavam-se exclusivamente ao prosseguimento de estudos de pós-graduação e $23 \%$ estavam procurando emprego.

\section{Instrumentos}

Para avaliar a autoeficácia utilizou-se a escala "Autoeficácia na Transição para o Trabalho" (AETT; Vieira \& Coimbra, 2005). O sucesso na transição para o trabalho foi avaliado através de duas escalas: "Satisfação com o Percurso Académico-Profissional" (SPAP; Vieira, 2012); e, "Satisfação no Trabalho" (ST; Vieira, 2012). Adicionalmente foi elaborado um breve questionário para avaliar a situação académico-profissional e o salário.

Autoeficácia na Transição para o Trabalho (AETT; Vieira \& Coimbra, 2005). A AETT é um instrumento de autorrelato constituído por 28 itens com formato de resposta tipo Likert com seis pontos (desde 1= nada confiante até $6=$ totalmente confiante). Esta escala avalia em que medida o sujeito confia na sua capacidade para realizar tarefas e lidar com desafios relacionados com a procura de emprego e com o início da atividade laboral. A AETT é constituída por três dimensões: (a) Autoeficácia na adaptação ao trabalho - avalia o grau de confiança na capacidade de adaptação ao mundo trabalho (12 itens); (b) Autoeficácia na regulação emocional - avalia o grau de confiança na autorregulação emocional durante o processo de procura de emprego (9 itens); e, (c) Autoeficácia na procura de emprego - avalia o grau de confiança no desempenho de comportamentos de procura de emprego (7 itens). 
Vários estudos têm evidenciado características psicométricas adequadas deste instrumento, seja em termos da sua validade de constructo (Vieira, 2012) como de estrutura fatorial (Vieira, Maia \& Coimbra, 2007). Vale ressaltar que foram também já realizados estudos de adaptação da AETT ao contexto brasileiro (Pelissoni, 2007; Soares, Polydoro \& Vieira, 2006).

No presente estudo, o índice de consistência interna para a escala total foi de .96 , para as subescalas de Autoeficácia na Adaptação ao Trabalho e Autoeficácia na Regulação Emocional foi de .93 e para a subescala Autoeficácia na Procura de Emprego foi de .83.

Satisfação com o Percurso Académico-Profissional (SPAP; Vieira, 2012).A SPAP é um instrumento de autorrelato constituído por 9 itens e apresenta uma escala de resposta tipo Likert de seis pontos (desde $1=$ totalmente insatisfeito/a até $6=$ totalmente satisfeito/a). Este instrumento é unidimensional e avalia o grau de satisfação relativamente a diversos aspectos relativos ao percurso académico e/ou profissional, tais como, por exemplo, o desenvolvimento de competências ou a realização das expectativas académico-profissionais. As características psicométricas da SPAP têm evidenciado a sua adequação (Vieira, 2012). O índice de consistência interna na presente investigação, tal como no estudo original, foi de 93 .

Satisfação no Trabalho (ST; Vieira, 2012). A ST é um instrumento de autorrelato composto por 19 itens que avalia o nível de satisfação no trabalho em três dimensões: (a) satisfação com as compensações do trabalho (7 itens) tais como a remuneração, o reconhecimento ou a acesso a oportunidades de desenvolvimento profissional; (b) satisfação com as funções do trabalho (6 itens) tais como o interesse pelas atividades desempenhadas ou a adequação das funções exercidas às habilitações académicas; e, (c) satisfação com as relações no trabalho (6 itens), tanto com colegas como com superiores. Os itens são respondidos numa escala tipo Likert de seis pontos (desde $1=$ totalmente insatisfeito/a até $6=$ totalmente satisfeito/a). A ST tem revelado qualidades psicométricas adequadas (Vieira, 2012) e, no presente estudo, os índices de consistência interna foram satisfatórios (.88 na subescala de satisfação com o conteúdo do trabalho; .84 na subescala de satisfação com as relações no trabalho; e, .85 na subescala de satisfação com as compensações do trabalho).

\section{Procedimento}

Os dados relativos à autoeficácia na transição para o trabalho foram recolhidos presencialmente nos grupos-turma dos estudantes durante o último semestre do curso (momento 1). Após a explicitação dos objetivos do estudo foi salientado o carácter voluntário da participação, bem como salvaguardada a confidencialidade dos resultados e distribuídos os consentimentos informados. Foi também referida a necessidade de disponibilizarem os endereços de correio eletrónico para o segundo momento de avaliação. Um ano após a conclusão do curso (momento 2), os participantes foram convidados a responder a um questionário on-line (por correio eletrónico) com o objetivo de avaliar a situação académico-profissional, a satisfação com o percurso académico-profissional, a satisfação no trabalho e o salário (quando aplicável).

Os dados obtidos foram analisados por meio de análises estatísticas do tipo descritivo e inferencial, utilizando-se o programa IBM SPSS Statistics (versão 24). Após a apresentação das médias e desvios-padrão, foram calculadas as correlações entre as variáveis independentes (as três dimensões da autoeficácia na transição para o trabalho) e as variáveis dependentes (a satisfação com o percurso académico-profissional e as três dimensões da satisfação no trabalho, nomeadamente, a satisfação com as compensações, com as funções e com as relações no trabalho). Finalmente, realizaram-se análises de regressão utilizando apenas as variáveis cuja correlação foi positiva e estatisticamente significativa, a fim de avaliar o poder preditivo da autoeficácia na transição para o trabalho no sucesso desta transição. Nas análises de regressão atendemos às orientações propostas por Field (2005), nomeadamente, procedemos às análises do diagrama de dispersão, dos resíduos, homocedasticidade, covarância nula e ausência de outliers, bem como à análise da multicolinearidade das variáveis independentes.

\section{Resultados}

Conforme pode ser observado na Tabela 1 , no que se refere à autoeficácia na transição para o trabalho, os participantes apresentaram uma média mais elevada na dimensão relacionada com confiança face à sua capacidade de adaptação ao trabalho $(M=4.76)$, por comparação com a dimensão da regulação emocional $(M=4.26)$ e da procura de emprego $(M=4.10)$. A média no grau de satisfação com o percurso académico-profissional foi de 4.10, o que evidencia que os participantes se encontram satisfeitos relativamente ao desenvolvimento de competências e às suas expectativas académico-profissionais. No grupo dos participantes que exercem uma atividade profissional, a satisfação com as relações laborais apresenta a média mais elevada $(M=4.71)$, seguida pela satisfação com as funções $(M=4.18)$ e pela satisfação com as compensações $(M=3.64)$. 
Tabela 1

Estatísticas Descritivas da Autoeficácia e do Sucesso na Transição para o Trabalho

\begin{tabular}{lcccc}
\hline & $n$ & Min-Máx & Média & Desvio-padrão \\
\hline 1. AETT-AT & 210 & $2.83-6.00$ & 4.76 & 0.63 \\
2. AETT-RE & 210 & $2.11-6.00$ & 4.26 & 0.89 \\
3. AETT-PE & 210 & $1.14-6.00$ & 4.10 & 0.89 \\
4. SPAP & 210 & $1.89-5.59$ & 4.10 & 0.80 \\
5. ST-C & 104 & $1.17-5.67$ & 3.64 & 0.97 \\
6. ST-F & 104 & $1.57-6.00$ & 4.18 & 0.99 \\
7. ST-R & 104 & $1.40-6.00$ & 4.71 & 0.77 \\
8. Salário (Euros) & 81 & $490-1200$ & 714 & 177 \\
\hline
\end{tabular}

Nota: AETT-AT = Autoeficácia na Adaptação ao Trabalho; AETT-RE = Autoeficácia na Regulação Emocional; AETT-PE = Autoeficácia na Procura de Emprego; SPAP = Satisfação com o Percurso Académico-profissional; ST-C = Satisfação com as compensações no trabalho; ST-F = Satisfação com as funções no trabalho; ST-R = Satisfação com as relações no trabalho

As correlações entre as três dimensões da autoeficácia (autoeficácia na adaptação ao trabalho, na regulação emocional e na procura de emprego) e os indicadores do sucesso na transição para o trabalho utilizados neste estudo, nomeadamente, a satisfação com o percurso académico-profissional, a satisfação no trabalho nas suas três dimensões (satisfação com as compensações, com as funções e com as relações no trabalho) e o salário, são apresentadas na Tabela 2. As dimensões da autoeficácia na adaptação ao trabalho e da autoeficácia na regulação emocional apresentam correlações positivas e significativas com a satisfação com o percurso académico-profissional e com as três dimensões da satisfação no trabalho (satisfação com as compensações, com as funções e com as relações no trabalho), mas não apresentam relação com o salário. Por sua vez, a autoeficácia na procura de emprego apresenta uma correlação positiva apenas com a satisfação com o percurso académico-profissional. Seguidamente realizamos análises de regressão com as dimensões da autoeficácia como variáveis independentes. Os quatro indicadores que revelaram correlações positivas e estatisticamente significativas com a autoeficácia, isto é, a satisfação com o percurso académico-profissional e as três dimensões da satisfação no trabalho (satisfação com as relações laborais, com as funções e com as compensações) foram consideradas nas análises de regressão como variáveis dependentes.

Tabela 2

Correlações entre Autoeficácia e Sucesso na Transição para o Trabalho

\begin{tabular}{lcccc}
\hline & $n$ & AETT-AT & AETT-RE & AETT-PE \\
\hline SPAP & 210 & $.27^{* *}$ & $.34^{* *}$ & $.15^{*}$ \\
ST-C & 104 & $.35^{* *}$ & $.25^{*}$ & .19 \\
ST-F & 104 & $.44^{* *}$ & $.30^{* *}$ & .10 \\
ST-R & 104 & $.48^{* *}$ & $.20^{*}$ & .11 \\
Salário & 81 & .00 & .10 & .07 \\
\hline
\end{tabular}

Nota: A Autoeficácia foi avaliada um ano antes dos indicadores de sucesso na transição para o trabalho. AETT-AT = Autoeficácia na Adaptação ao Trabalho; AETT-RE = Autoeficácia na Regulação Emocional; AETT-PE = Autoeficácia na Procura de Emprego; SPAP = Satisfação com o Percurso Académico-profissional; ST-C = Satisfação com as compensações no trabalho; ST-F = Satisfação com as funções no trabalho; ST-R = Satisfação com as relações no trabalho

A análise de regressão revela que a autoeficácia na adaptação ao trabalho $(t=2.11, p<.05)$ e a autoeficácia na autorregulação emocional $(t=3.77, p<.001)$ explicam $14 \%$ da variância da satisfação com o percurso académico-profissional $\left[F(3,206)=10.88, \mathrm{p}<.001 ; \mathrm{R}^{2}=.14\right]$, embora a autoeficácia na procura de emprego não tenha evidenciado valor preditivo $(t=0.87, p=.38)$.
Nas análises de regressão efetuadas com o objetivo de explorar o efeito preditor da autoeficácia sobre a satisfação no trabalho, optou-se por utilizar como variáveis independentes as dimensões da autoeficácia na adaptação ao trabalho e da autoeficácia na autorregulação emocional, pelo facto de apenas estas terem revelado correlações positivas 
estatisticamente significativas com as três dimensões da satisfação no trabalho.

Nas análises de regressão verifica-se que a autoeficácia na adaptação ao trabalho explica $13 \%$ da variância da satisfação com as compensações no trabalho, $\left[\mathrm{R}^{2}=.13 ; F(2,101)=7.66, p<.01 ; t=2.84, p<.01\right]$, $21 \%$ da variância da satisfação com as funções no trabalho $\left[\mathrm{R}^{2}=.21 ; F(2,101)=13.07, p<.001 ; t=3.84, p<.001\right] \mathrm{e}$ $24 \%$ da variância da satisfação com as relações no trabalho $\left[\mathrm{R}^{2}=.24 ; F(2,101)=15.90, p<.001 ; t=5.11, p<.001\right]$. Por sua vez, a autoeficácia na autorregulação emocional não evidenciou valor preditivo $(t=0.82, p=.41 ; t=0.91$, $p=.37 ; t=0.60, p=.54$ ).

\section{Discussão e conclusão}

Partindo do Modelo Social Cognitivo da Transição para o Trabalho (MSTT; Vieira, 2012), este estudo visou analisar se a autoeficácia na transição para o trabalho de estudantes do último ano do Ensino Superior é capaz de predizer o sucesso obtido nesta transição, um ano após a conclusão do curso. Os resultados evidenciam que a autoeficácia na transição para o trabalho contribuiu para predizer a satisfação com o percurso académico-profissional e a satisfação no trabalho, nas suas três dimensões (compensações, funções e relações no trabalho). Estes resultados estão em linha com outros estudos (Abele \& Spurk, 2009; Ballout, 2009; Pinquart, Juang \& Silbereisen, 2003; Vieira, 2012), nomeadamente no que diz respeito à autoeficácia e à satisfação.

Porém, embora o modelo teórico utilizado tenha sido o mesmo, na investigação realizada por Vieira (2012) a autoeficácia foi capaz de prever o salário, resultado que não se constatou no presente estudo. Com efeito, mesmo utilizando uma metodologia semelhante, não se verificou qualquer relação entre o salário e a autoeficácia. Esta diferença nos resultados pode ser devida a vários fatores. Um primeiro fator diz respeito aos próprios valores reportados face ao salário que no presente estudo apresentam uma variabilidade francamente menor (entre 490-1200 euros) por comparação com o estudo de Vieira (2012; salário entre 350-2500 euros). Outro fator pode estar relacionado com a diferença no número de participantes que reportaram o salário nos dois estudos (no presente estudo, apenas 81, por contraposição aos 140 participantes que o fizeram no referido estudo). Adicionalmente, ao analisarem a relação entre a autoeficácia profissional e o sucesso na carreira, ao longo do tempo, Spurk \& Abele (2014) concluem que o efeito da autoeficácia no sucesso subjetivo (como é o caso da satisfação com o trabalho) é mais imediato do que no sucesso objetivo (como é o caso do salário). Assim, uma das limitações que se poderá apontar ao presente estudo diz respeito ao pouco tempo decorrido após a conclusão da graduação (cerca de um ano). Consequentemente, estudos futuros deverão avaliar o sucesso profissional não apenas após um ano da conclusão da graduação, mas também num período posterior da vida laboral.

Apesar do presente estudo ter contribuído para reafirmar o importante papel que a autoeficácia possui na transição para o trabalho, a amostra é constituída por graduados de uma mesma instituição de ensino superior e foi apenas investigada a parte do Modelo Social Cognitivo da Transição para o Trabalho (MSTT; Vieira, 2012) que diz respeito à influência direta da autoeficácia sobre o sucesso nesta transição. Estudos futuros deverão ser realizados junto de outras amostras e poderão explorar também outras hipóteses colocadas pelo referido modelo teórico, seja ao nível das fontes de autoeficácia da transição para o trabalho (apoio social percepcionado e exploração vocacional), seja na relação entre a autoeficácia, as expectativas de resultado na procura de emprego e os objetivos profissionais (conforme Figura 1).

Os desafios na transição para o trabalho são cada vez maiores e este estudo demonstrou que a autoeficácia possui um papel facilitador neste processo. Consequentemente, as instituições de ensino superior deveriam apostar em intervenções psicoeducativas direcionadas ao desenvolvimento das crenças de autoeficácia dos seus estudantes. Tais intervenções poderiam ser baseadas nas fontes de autoeficácia propostas por Bandura (1986;1997). Mais especificamente, o presente estudo evidenciou que a autoeficácia na transição para o trabalho e, em particular, a sua dimensão relacionada com a confiança na capacidade adaptação ao trabalho, foi capaz de predizer a satisfação com o trabalho. Conjugando este resultado com uma das principais fontes de autoeficácia - experiências prévias de sucesso - as instituições de ensino superior deverão intensificar, ao longo do percurso formativo do estudante, as oportunidades de prática profissional em contextos reais de trabalho que sejam gradualmente mais exigentes. Desta forma será possível criar oportunidades que fortaleçam o sentido de autoeficácia na adaptação ao trabalho. Além disso, é igualmente importante que as instituições de ensino superior transmitam o valor do desenvolvimento vocacional e da aprendizagem ao longo da vida, ao mesmo tempo que enfatizam a relevância e a necessidade de o indivíduo continuar a explorar os interesses em novas áreas e a atualizar as suas competências (Lent, Hackett \& Brown, 2004).

No cruzamento entre a investigação e a prática, sugere-se a implementação de programas de intervenção 
com vista à preparação para a transição para o trabalho, ao longo do percurso formativo dos estudantes, mas também a sua avaliação em termos da autoeficácia na transição para o trabalho e do subsequente sucesso nesta transição.

\section{Referências}

Abele, A. E. \& Spurk, D. (2009). The longitudinal impact of self-efficacy and career goals on objective and subjective career success. Journal of Vocational Behavior, 74, 53-62.

Ballout, H. I. (2009). Career commitment and career success: moderating role of self-efficacy. Career Development International, 14(7), 655-670.

Bandura, A. (1986). Social foundations of thought and action: A social cognitive theory. Englewood Cliffs, NJ: Prentice Hall.

Bandura, A. (1989). Human agency in social cognitive theory. American Psychologist, 44(9), 1175-1184.

Bandura, A. (1991). The changing icons in personality psychology. In J. H. Cantor (Ed.), Psychology at Iowa: Centennial essays (pp. 117-139). Hillsdale, NJ: Erlbaum.

Bandura, A. (1997). Self-efficacy: The exercise of control. New York: Freeman.

Bernstein, L. E. (2014). The perceived importance of vuca-driven skills for $21^{\text {st }}$ century leader success and the extent of integration of those skills into leadership development programs. Tese de doutoramento. Des Moines, Iowa: Drake University.

Betz, N. E. (2004). Contributions of self-efficacy theory to career counseling: A personal perspective. The Career Development Quarterly, 52, 340-353.

Blustein, D. L. (1992). Applying current theory and research in career exploration to practice. The Career Development Quarterly, 41, 174-184.

Blustein, D. L. (1997). A context-rich perspective of career exploration across the life roles. The Career Development Quarterly, 45, 260-274.

Blustein, D. L., Prezioso, M. S. \& Schultheiss, D. P. (1995). Attachment theory and career development: Current status and future directions. The Counseling Psychologist, 23, 416-432.

Bowlby J. (1982). Attachment and loss. Vol. 1: Attachment (2nd ed.). New York: Basic Books.

Campos, B.P. \& Coimbra, J.L. (1991). Consulta psicológica e exploração do investimento vocacional. Cadernos de Consulta Psicológica, 7, 11-19.

Campos, B.P. \& Coimbra, J.L. (1992). Orientação Vocacional e Gestão de Recursos Humanos. Comunicação apresentada no Forum "Euroformação/Eurotraining". Lisboa.

Coimbra, J.L., Parada, F. \& Imaginário, L. (2001). Formação ao longo da vida e gestão da carreira. Lisboa: Ministério do Trabalho e da Solidariedade, Direção Geral do Emprego e Formação e Formação Profissional.

Field, A. (2005). Discovering statistics using SPSS (2nd Ed.). London: Sage.

Fernaud, E.H., Sapena, Y.R., Negrín, F., De la Rosa, C.I.R, \& Hernández, B. (2011). Empleabilidad Percibida y Autoeficacia para la Búsqueda de Empleo en Universitarios. Revista de Psicología del Trabajo y de las Organizaciones, 27(2), 131-142.

Pelissoni, A. M. (2007). Auto-eficácia na transição para trabalho e comportamentos de exploração de carreira em licenciandos. Dissertação de mestrado não publicada. Universidade de Campinas, Campinas, SP.

Lent, R.W., Brown, S. D. \& Hackett, G. (1994). Toward a unifying social cognitive theory of career and academic interest, choice, and performance. Journal of Vocational Behavior, 45, 79-122.

Locke, E. A. \& Latham, G. P. (2002). Building a practically useful theory of goal setting and task motivation: A 35-year odyssey. American Psychologist, 57(9), 705-717.

Santos, A. A. A., Mognon, J. C., \& Joly, M. C. R. A. (2011). Autoeficácia na transição para o trabalho em formandos de engenharia. Revista Brasileira de Orientação Profissional, 12(2), 197-204.

Schunk, D.H. (1989) Self-efficacy and Achievement Behaviors. Educational Psychology Review, 1(3), 173-207.

Shaffer, L.S., \& Zalewski, J.M. (2011). Career Advising in a VUCA Environment. The Journal of the National Academic Advising Association, 31(1), 13-20.

Soares, A. M., Polydoro, S. A. S., \& Vieira, D. (2006). Adaptação da Escala Autoeficácia da transição para mundo do trabalho (AETT) para realidade brasileira. II Congresso Psicologia: Ciência e Profissão. Universidade de São Paulo, São Paulo, 5-9 Setembro. 
Spurk, D. \& Abele, A. E. (2014). Synchronous and time-lagged effects between occupational self-efficacy and objective and subjective career success: Findings from a four-wave and 9-year longitudinal study. Journal of Vocational Behavior, 84, 119-132.

Wood, R. \& Bandura, A. (1989). Social cognitive theory of organizational management. Academy of Management Review, 14, 361-384.

Vieira, D.A. (2012). Transição do ensino superior para o trabalho: O poder da autoeficácia e dos objetivos profissionais. Porto: Politema/Vida Económica.

Vieira, D. A. (2017). Orientação profissional e de carreira no Século XXI: as possibilidades das competências socioemocionais. XIII Congresso Brasileiro de Orientação Profissional e de Carreira. Campinas-São Paulo: Universidade São Francisco, 19-22 de setembro.

Vieira, D. \& Coimbra, J. L. (2005). University-to-work transition: The development of a self-efficacy scale. Comunicação apresentada no Congresso Internacional da International Association of Vocational and Educational Guidance (IAVEG), Careers in context: New challenges and tasks for guidance and counselling (p.106). Lisboa: Universidade de Lisboa.

Vieira, D., Maia, J. e Coimbra, J. L. (2007). Do ensino superior para o trabalho: Análise fatorial confirmatória da escala de Autoeficácia na Transição para o Trabalho (AETT). Avaliação Psicológica, 6(1), 3-12.

Vondracek, F. W., Lerner, R. M. \& Schulenberg, J. E. (1986). Career Development: A life-spa, development approach. Hillsdale, NJ: Erlbaum.

Young, R. A. (1994). Helping adolescence with career development: The active role of parents. The Career Development Quarterly, 42, 195-203.

Recebido 16/02/2018

Reformulado 19/07/2018

Aceite Final 07/10/2018

Sobre as autoras

Diana Aguiar Vieira é Doutora em Psicologia pela Universidade do Porto. Investigadora do Centro de Estudos Organizacionais e Sociais do Politécnico do Porto (CEOS.PP) e Professora Adjunta do Instituto Superior de Contabilidade e Administração do Instituto Politécnico do Porto, Portugal.

Maria Theotonio é Mestranda no Mestrado em Psicologia da Universidade de São Francisco, Campinas, São Paulo, Brasil. 